\title{
ADHESIVE PROPERTIES AND SENSITIVITY TO ANTIFUNGAL DRUGS OF CANDIDA ALBICANS, WHICH ARE RELEASED FROM PATIENTS OF GASTROENTEROLOGICAL PROFILE WITH CANDIDIASIS OF THE MUCOSA OF THE UPPER PART OF THE DIGESTIVE TRACT
}

\author{
Inessa Kushnirenko \\ Department of gastroduodenal disorders, dietology and nutritional care \\ SI "Institute of Gastroenterology NAMS of Ukraine» \\ 96 Slobozhansky ave., Dnipro, Ukraine, 49074 \\ inessa.kushnirenko@gmail.com
}

\begin{abstract}
Candida albicans were released from 146 loci from 89 patients in order to perform the investigation. The fourth stage of contamination by Candida albicans in the scrape from the tongue and candidiasis of the esophagus or/and the stomach during microbiologic investigations of the biopsy materials were the main criterion for this research. HIV-infected patients and patients in whom antibacterial therapy was done less than in four weeks were excluded from the investigation. Microorganisms were taken from the next biopsy materials: oropharyngeal area included 81, esophagus contained 30, stomach included 24 in general (the body of the stomach contained 14 and antrum included 10, gastric juice included 11. Adhesion evaluation was done by microtechnique in U-shaped microplates with formalized erythrocytes $0(\mathrm{I}), \mathrm{Rh}+$. According to the results of the investigation, the released fungi in $51,37 \%$ of cases were characterized as nonadherent ones, in $28,77 \%$ of cases it was defined as low level of adhesiveness and only in $17,12 \%$ of cases it was determined as average and high level of the adhesiveness. Adhesiveness increase was not associated with the increase of the contamination of the oral cavity and with the severity of the damage of the mucosa of the esophagus or/and the stomach. In $97,8 \%$ of cases, strains of Candida albicans were sensitive to fluconazole, in $75,6 \%$ of cases, strains were sensitive to itraconasole and in $24,4 \%$ of cases they were determined as moderately sensitive and resistant that initiates fluconazole as the drug of the choice for the treatment of the candidiasis of the mucosa of the upper part of the digestive tract. So, received data determines the necessity to detect factors of dysfunction of antifungal resistance of the mucosa that detects the development of its candidal damage.

Keywords: candidiasis, mucosa, adhesion, sensitivity, digestive tract.
\end{abstract}

\section{Introduction}

Candida albicans are opportunistic pathogens, which colonize the different anatomic loci, including skin, oropharyngeal area, gastrointestinal tract, but conditions due to which there is a transition of commensal form of the existence to pathogenic one have not studied yet. Ability to the adhesion, protein secretion, hypha formation and phenotypic peculiarities determine the main factors of the virulence of Candida albicans [1-4]. Gastrointestinal tract is the main reservoir for Candida albicans, and the stage of colonization is the influence of the immune system of the host and Candida spp. [5-9]. About this fact, there is an interesting fact of P. Sampaio with co-operation according to which genetic variants of one or other strain which was taken in the patient before and after treatment were analyzed and adapted in the human body, which result was an increase of the virulence in the experiments on mice [10]. It is known that ability of Candida albicans to the adhesion on cells defines the stage of the virulence of the fungus, and also hyphal form is the sign of the pathogenicity whereas yeast stage is not associated with the ability to the pathogenic action [11-15]. However, according to S. E. Grubb's data, yeast formations are able to adhere to the endothelium and migrate into tissues in morphological changes and number of adhesive yeast containing forms of fungi in this experiment was higher than in pseudohyphal and hyphal forms [16]. Important information was defined in the investigations of T. J. Rast in co-operation. They determined that the effect of immune response formation of the macroorganism depends on epithelial cells, which control the balance of the microflora on their surface, which is dose-dependent from the number of Candida albicans on the mucosa [17]. Other experimental investigations determine that the small 
level of colonization is determined by the dissemination of Candida albicans in kidneys, and spread colonization can occur during morphological form of the fungi and even during yeast containing form [18]. According to clinical investigations that are devoted to the adhesiveness of fungi which were released from patients, adhesive properties of fungi are associated with the severity of the disease. So, according to the results by E. A. Kerimov, the increase of the stage of Candida albicans seeding in patients from feces correlates with the ability of fungi to the adhesion to the epithelial cells [19], and according to the information by S. A. Lisovskaya with co-operation, adhesive properties of strains, which were received from the skin surface correlate with clinical signs of the disease and the stage of contamination by Candida albicans [20]. In general, received data determines the necessity to study commensalism and pathogenicity of Candida albicans.

\section{Aim}

The aim of the investigation was to study adhesive properties of Candida albicans, which were released in different loci of patients of gastroenterological profile with the candidiasis of the mucous membrane of the upper part of the digestive tract.

\section{Materials and Methods}

Fungi Candida albicans were released from 89 patients in order to perform the investigation. The fourth stage of contamination by Candida albicans in the biological material of the scrape of the tongue and also the presence of macroscopic signs of candidiasis of the esophagus during fibrogastroduodenoscopy with cytological study were the main criteria for the investigation. HIV-infected patients and patients in whom antibacterial therapy was done less than in four weeks were excluded from the investigation. Quantitative evaluation of fungi in the scrape from the tongue was done according to the stage of the massiveness of microbial contamination (SMC) such as: the first stage of contamination presents that the number of colonies on Petri dish was up to 25 colonies, that corresponds to physiological norm; the second one contained from 25 to 100 colonies; the third stage of contamination presented more than 100 colonies and the fourth one contained more than 300 colonies. Patients were divided into three groups according to the microbiological investigation. The first group contained (1) 45 patients with the fourth stage of fungi contamination of Candida albicans in the scrape from the tongue, i.e. oropharyngeal candidiasis (OPC), and superficial growth of fungi in biopsy materials. The second one included (2) 39 patients, in which during microbiological investigation invasive growth of fungi in biopsy materials was observed. The third group contained (3) 5 patients without OPC and without fungi growth in biopsy materials. The average age of patients of the first group was $(47,0 \pm 12,2)$ years, the age of the second and the third groups was $(50,6 \pm 15,2)$ and $(46,3 \pm 13,3)$ years, correspondingly. Microorganisms were released from the next biopsy materials: oropharyngeal area included 81, esophagus presented 30 , and stomach included 24 (in general), from which stomach body included 14 and antrum included 10, gastric juice presented 11. In general, Candida fungi were investigated from 146 loci. Identification of released cultures was done according to methodical recommendations „Microbiological diagnostics of candidal infection" (2006) due to the set API Candida (Biomerieux ${ }^{\circledR}$ SA). The set ATB FUNGUS 3 (Biomerieux ${ }^{\circledR}$ SA) was used to determine the sensitivity to antimycotic drugs with determination of minimal inhibitive concentration (MIK) to 5-flucytosine, amphotericin B, fluconazole, itraconasole, voriconazole. Determination of antimycotic drugs to these preparations was done visually due to the analogue scale, set for visual evaluation of results ATB FUNGUS 3 was used by strip displacement. For each antimycotic drugs the result evaluation was begun from the least concentration, compared the growth in cavities with the growth in control cavities with next evaluation by five point scale. Luminal concentrations CLSI/NCCLS (mg/l) for Candida spp. were determined according to such recommendations as "Reference Method for Broth Dilution Antifungal Susceptibility Testing of Yeasts. NCCLS M27-A2, August 2002", "CLSI Summary Minutes Subcommittee on Antifungal Susceptibility Tests - Tampa, Florida - 8 January 2005". Determination of adhesiveness of Candida spp., released from examined patients was done by the members of the laboratory of general microbiology of SI "Institute of Epidemiology and Infectious Diseases named after L. Gromashevsky NAMS of Ukraine”. Adhesion evaluation was done by 
microtechnique in U-shaped microplates. Formalized erythrocytes $0(\mathrm{I}), \mathrm{Rh}+$ were used for the investigation. Native erythrocytes were washed twice by the buffer $(0,1 \mathrm{M}$ of sodium phosphate solution, which was prepared on isotonic solution of chloride of sodium, $\mathrm{pH} 7,2-7,2)$ and it was centrifugated at 3000 rotation/min. Erythrocytes suspension $100 \mathrm{mln} / \mathrm{ml}$ was done on this buffer. Microorganisms were grown during 1-2 days on the Saburo environment, microorganisms suspension was done $10^{9}$ cells $/ \mathrm{ml}$, it was washed by phosphate buffer twice ( $\left.\mathrm{pH} 7,2-7,3\right)$. Further, in cavities of U-shaped microplates $0,1 \mathrm{ml}$ of suspension of investigated microorganisms was placed, after that $0,1 \mathrm{ml}$ of formalized erythrocytes was added in each cavity. The mixture was incubated at $37{ }^{\circ} \mathrm{C}$ during $30 \mathrm{~min}$. at permanent shaking. Swabs were done on fat-free glass and painted according to the method Romanovskyi-Himze. Adhesion was studied under the light microscope due to such indices:

1) medial index of adhesion is the average number of microbes, that were attached to the first erythrocyte (no less than 25 ones);

2) coefficient of erythrocytes in the adhesive process presents the percent of erythrocytes that have adhesive microbes on their surface;

3 ) index of adhesiveness is the average number of microbic cells on one erythrocyte, that participates in adhesive process should be calculated in this way:

Index of adhesiveness $=$ medial index of adhesion $\times 100 / C$;

Microorganisms were non-adherent at the index of adhesiveness $<1,74$, low stage of adhesion from 1,76-2,5, medial stage of adhesion from 2,51-4,0, high stage of adhesion, when index of adhesion was higher than 4,0 [21].

\section{Results}

According to received results, all fungi of Candida albicans were released from 146 loci of examined patients of gastroenterological pathology with candidiasis of the mucosa of the upper region of the digestive tract were characterized as non-adherent (non-adhesive) ones. Characteristics of adhesive properties which were released in fungi in general were presented on the Fig. 1.

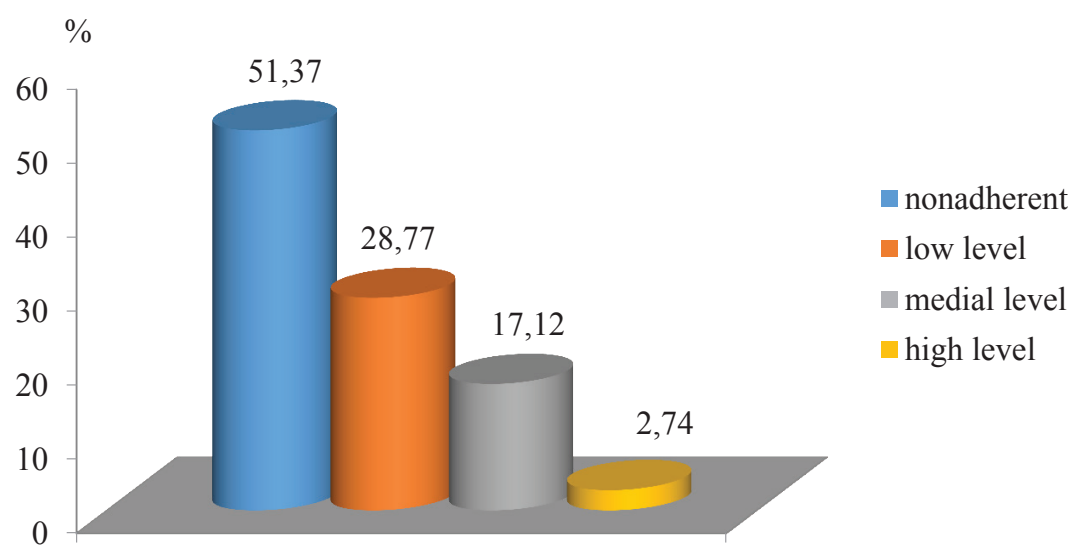

Fig. 1. Division of released Candida albicans according to the level of adhesiveness

As above seen in more than half of cases the fungi which were characterized as non-adherent ones were released, and in less than third part of them presented the low stage of adhesiveness and only the fifth part of them were characterized by the medial and high properties of adhesiveness.

Division of the fungi which were released in scrape of the tongue according to adhesive properties in groups is presented on the Fig. 2. 


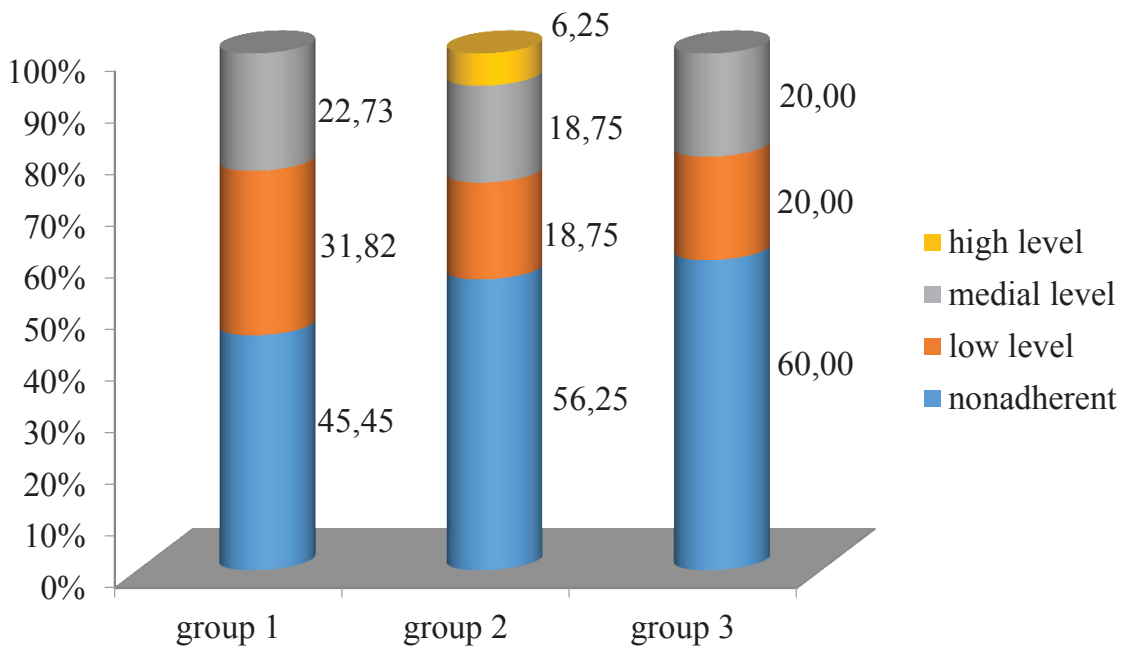

Fig. 2. Adhesive properties of Candida albicans, which were released in scrape of the tongue, in groups

As presented data showed, in major part of patients of all groups epy fungi with non-adherent properties were released, but in patients of the first group fungi with non-adherent properties were detected by $10,8 \%$ and by $14,55 \%$ rarer, comparably with the second and the third one, however without accurate difference of indices $(p>0,05)$. The fungi with adhesiveness of medial stage in all groups were released in equal frequency in the fifth part of cases and only in $6,25 \%$ of cases fungi were at the high adhesive level and they were detected only in the second group with invasion in the mucous membrane. Characteristics of fungi adhesiveness, released from esophagus biopsy materials, are presented on the Fig. 3.

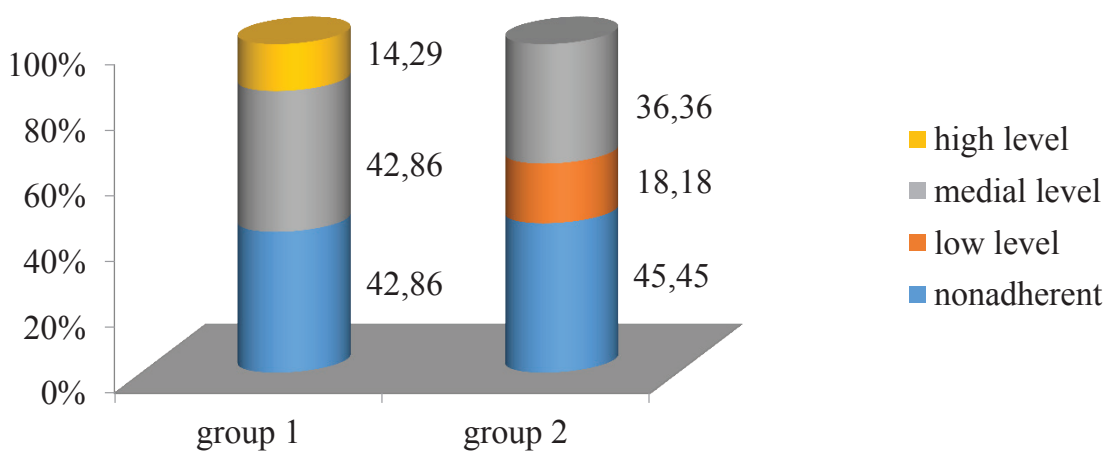

Fig. 3. Characteristics of adhesive properties of Candida albicans released from biopsy materials of the esophagus

7 strains were released from the lining of the esophagus in the first group, they were non-adherent and only one patient had high adhesiveness of fungi from this group (14,29\%). There was determined the high level of adhesiveness. In 22 patients of the second group in whom invasive growth of fungi was detected, released fungi Candida albicans were characterized as non-adherent ones, in the fifth part of cases presented low level of adhesiveness and more than in the third part presented medial low of adhesiveness. The fungi, released from the body and antrum of the stomach, were analyzed. Small number of investigations in these loci didn't allow receive the accurate difference, but there is an interesting fact that there is determination of medial and high adhesive properties of released fungi only in patients of the second group both in the body, in the third part of results $(27,27 \%)$, and in the antrum, in more than the fifth part $(22,2 \%),(p>0,05)$. Fungi were 
released in 11 patients in the gastric juice: in 4 from the first group and in 7 from the second one. Released strains were characterized as non-adherent and low adhesive almost with equal frequency $-45,45 \%(n=5)$ and $54,55 \%(n=6)$, correspondingly.

It was decided by us to analyze the frequency of determination of contamination in examined patients in comparison with adhesive properties of fungi to determine the question about adhesive properties' influence of released microorganisms on the massiveness of contamination of oropharyngeal area by the fungi. Results are presented on the Fig. 4.

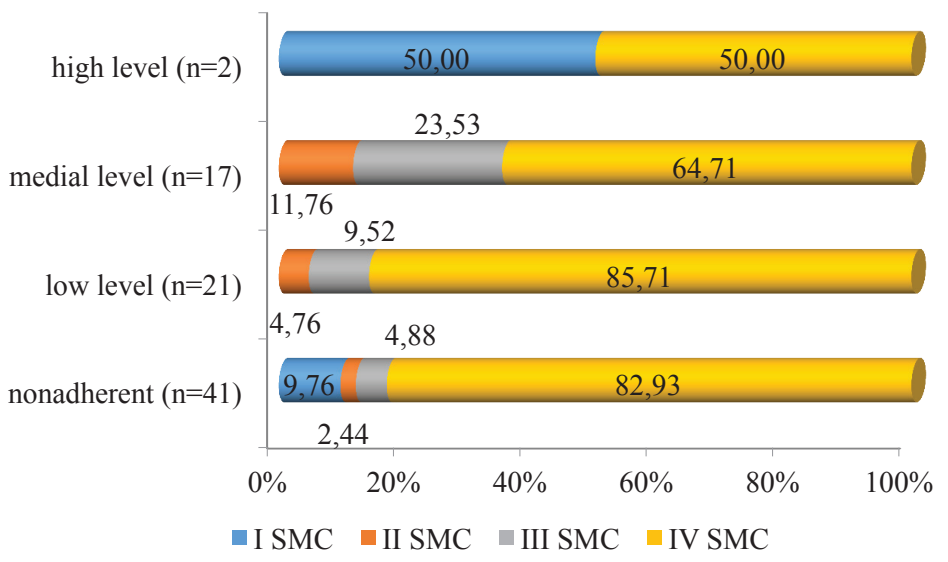

Fig. 4. Adhesive properties of Candida albicans in comparison with different SMC by fungi of oropharyngeal area in patients with gastroenterological pathology

According to the data, the high stage of adhesive properties does not provide the occurrence of maximal SMC by Candida albicans in patients of gastroenterological profile. Possible influence of adhesive properties of fungi was evaluated i. e. the depth of the damage of the mucous membrane of the esophagus and stomach was determined according to the results of biopsy materials (Fig. 5).

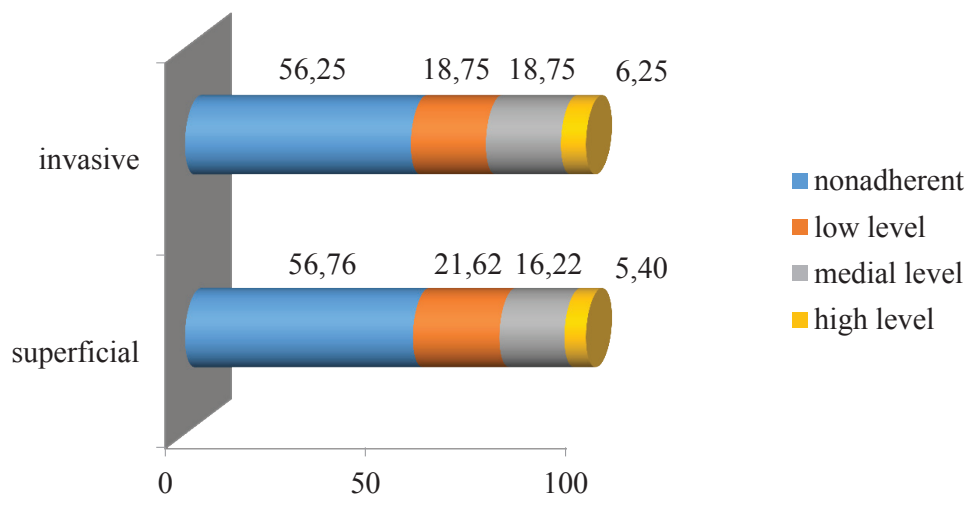

Fig. 5. Evaluation of correlation of the character of damage of the mucosa of the upper part of the digestive tract and adhesive properties of Candida albicans

As it was shown, adhesive properties of released fungi didn't affect the character of mucosa damage, however at superficial candidiasis of the mucosa and at invasive character of the growth the division of adhesiveness was almost equal.

The question of azole resistance was important in order to perform the adequate therapy. The investigation of 45 fungi strains on sensitivity to antimycotic was done by us. $91,1 \%$ strains were susceptible to flucytosine $(n=41)$, moderately resistant $-4,4 \%(n=2)$, resistant $-4,4 \%(2)$. All released strains $(100,0 \%)$ were sensitive to amphotericin B. Determination of sensitivity to azole group defined that, $97,8 \%(n=44)$ of strains were susceptible to fluconazole, $75,6 \%$ of strains were sensitive to itraconasole $(n=34)$ and $100,0 \%$ of strains were susceptible to voriconazole. The 
number of moderately sensitive to fluconazole contained 2,2 \% $(\mathrm{n}=1)$, to itraconasole was $17,8 \%$ $(n=8)$. Resistant to itraconasole contained $6,6 \%(n=3)$ of investigated strains, whereas no one was resistant to fluconazole. MIC of fluconazole for $66,7 \%(n=30)$ of strains was the concentration of $1 \mathrm{mg} / \mathrm{l}$, for $15,6 \%(\mathrm{n}=7)-2 \mathrm{mg} / \mathrm{l}$, for $6,7 \%(\mathrm{n}=3)-4 \mathrm{mg} / \mathrm{l}$, for $8,8 \%(\mathrm{n}=4)-8 \mathrm{mg} / \mathrm{l}$ and 1 strain of MIC equalized $32 \mathrm{mg} / 1$. MIC for $75,6 \%(\mathrm{n}=34)$ of strains was $0,125 \mathrm{mg} / 1$, for $8,9 \%(\mathrm{n}=19)$ of strains was 0,25 and $0,5 \mathrm{mg} / 1$, and in $6,6 \%(\mathrm{n}=3)-1 \mathrm{mg} / \mathrm{l}$. For major part of released strains $84,5 \%(n=38)-$ MIC of voriconazole equalized $0,06 \mathrm{mg} / 1$, for $11,1 \%(\mathrm{n}=5)-0,125 \mathrm{mg} / 1$, for $2,2 \%$ $(\mathrm{n}=1)-0,25$ and $1 \mathrm{mg} / \mathrm{l}$.

\section{Discussion}

The results of done investigation did not detect the interrelation of the development of the candidiasis of the mucosa of upper part of the digestive tract in patients of gastroenterological profile with adhesive properties of Candida albicans neither in the aspect of the stage of contamination of oropharyngeal area, nor in the damage of the mucosa of the esophagus and/or stomach, so in major part of cases the defined fungi were characterized as non-adherent ones. Such data determined the necessity to search for new factors of disorders of the system of antifungal resistance, which give rise to Candida albicans growth on the mucosa.

Determination of sensitivity of released fungi defined the level of sensitivity of released strains of Candida albicans to fluconazole that determines fluconazole as the drug of choice to perform empiric therapy during the treatment. The results of moderate sensitivity and resistance to itraconasole in general contained $24,4 \%$, which should not be used for drug's use for candidal infection. Dosedependence of the effect during treatment should be taken into consideration, so the prescription of adequate dose of azole drug is one of the positive effects during the treatment. Even at the low level of MIC of fluconazole, it should be considered the necessity of dose prescription of fluconazole in correspondence with body weight of the patient to receive proved effect from the treatment.

\section{Conclusions}

1. Candida albicans, which were released from 146 loci and 89 patients of gastroenterological pathology and candidiasis of the mucosa of the upper part of the digestive tract, in $51,37 \%$ of cases were characterized as non-adherent ones, in 28,77\% as low stage of adhesiveness and only in $17,12 \%$ of cases presented average and high stage of adhesiveness.

2. Increase of adhesiveness of Candida albicans was not associated with neither increase of contamination, nor the severity of the damage of the mucosa of the esophagus and/or stomach.

3. $97,8 \%$ of strains of Candida albicans were sensitivity to fluconazole, $75,6 \%$ of strains - to itraconasole with definition of $24,4 \%$ as moderately sensitive and resistant, and fluconazole was a drug of choice for the treatment of candidiasis of the mucosa of the upper part of the digestive tract.

4. Results of the investigation determined the necessity to detect factors of the damage of the system of antifungal resistance of the mucosa, that cause the development of Candida albicans damage.

\section{Acknowledgments}

The author expresses gratitude to members of the laboratory of medical microbiology of SI "Institute of Epidemiology and Infectious Diseases named after L. Gromashevsky NAMS of Ukraine” Professor O. I. Polischuk and PhD O. V. Pokas.

\section{References}

[1] Yang, Yu.-L. (2003). Virulence factors of Candida species. J. Microbiol Immunol Infect., 36, $223-228$.

[2] Mohandas, V., Ballal, M. (2011). Distribution of Candida Species in different clinical samples and their virulence: Biofilm formation, proteinase and phospholipase production: A study on hospitalized patients in Southern India. Journal of Global Infectious Diseases, 3 (1), 4. doi: 10.4103/0974-777x.77288

[3] Imron Nasution, A. (2013). Virulence Factor and Pathogenicity of Candida albicans in Oral Candidiasis. World Journal of Dentistry, 4, 267-271. doi: 10.5005/jp-journals-10015-1243 
[4] Hebecker, B., Naglik, J. R., Hube, B., Jacobsen, I. D. (2014). Pathogenicity mechanisms and host response during oral Candida albicans infections. Expert Review of Anti-Infective Therapy, 12 (7), 867-879. doi: 10.1586/14787210.2014.916210

[5] Zhu, W., Filler, S. G. (2010). Interactions ofCandida albicanswith epithelial cells. Cellular Microbiology, 12 (3), 273-282. doi: 10.1111/j.1462-5822.2009.01412.x

[6] Kumamoto, C. A. (2011). Inflammation and gastrointestinal Candida colonization. Current Opinion in Microbiology, 14 (4), 386-391. doi: 10.1016/j.mib.2011.07.015

[7] Glittenberg, M. T., Kounatidis, I., Christensen, D., Kostov, M., Kimber, S., Roberts, I., Ligoxygakis, P. (2011). Pathogen and host factors are needed to provoke a systemic host response to gastrointestinal infection of Drosophila larvae by Candida albicans. Disease Models \& Mechanisms, 4 (4), 515-525. doi: $10.1242 / \mathrm{dmm} .006627$

[8] Gow, N. A., Hube, B. (2012). Importance of the Candida albicans cell wall during commensalism and infection. Current Opinion in Microbiology, 15 (4), 406-412. doi: 10.1016/j.mib.2012.04.005

[9] Eggimann, P., Pittet, D. (2014). Candida colonization index and subsequent infection in critically ill surgical patients: 20 years later. Intensive Care Medicine, 40 (10), 1429-1448. doi: 10.1007/s00134-014-3355-Z

[10] Sampaio, P., Santos, M., Correia, A., Amaral, F. E., Chavéz-Galarza, J., Costa-de-Oliveira, S. et. al. (2010). Virulence Attenuation of Candida albicans Genetic Variants Isolated from a Patient with a Recurrent Bloodstream Infection. PLoS ONE, 5 (4), e10155. doi: 10.1371/journal.pone.0010155

[11] Bernhardt, J., Herman, D., Sheridan, M., Calderone, R. (2001). Adherence and Invasion Studies of Candida albicans Strains, Using In Vitro Models of Esophageal Candidiasis. The Journal of Infectious Diseases, 184 (9), 1170-1175. doi: 10.1086/323807

[12] Biasoli, M. S., Tosello, M. E., Magaro, H. M. (2002). Adherence of Candida strains isolated from the human gastrointestinal tract - Adharenz von Candida-Isolaten aus dem menschlichen Gastrointestinaltrakt. Mycoses, 45 (11-12), 465-469. doi: 10.1046/j.1439-0507.2002.d01-123.x

[13] Mayer, F. L., Wilson, D., Hube, B. (2013). Candida albicans pathogenicity mechanisms. Virulence, 4 (2), 119-128. doi: 10.4161/viru.22913

[14] 14. Gow, N. A. R., van de Veerdonk, F. L., Brown, A. J. P., Netea, M. G. (2011). Candida albicans morphogenesis and host defence: discriminating invasion from colonization. Nature Reviews Microbiology. doi: $10.1038 /$ nrmicro2711

[15] Williams, D. W., Jordan, R. P. C., Wei, X.-Q., Alves, C. T., Wise, M. P., Wilson, M. J., Lewis, M. A. O. (2013). Interactions of Candida albicans with host epithelial surfaces . Journal of Oral Microbiology, 5 (0). doi: 10.3402/jom.v5i0.22434

[16] Grubb, S. E. W., Murdoch, C., Sudbery, P. E., Saville, S. P., Lopez-Ribot, J. L., Thornhill, M. H. (2009). Adhesion of Candida albicans to Endothelial Cells under Physiological Conditions of Flow. Infection and Immunity, 77 (9), 3872-3878. doi: 10.1128/iai.00518-09

[17] Rast, T. J., Kullas, A. L., Southern, P. J., Davis, D. A. (2016). Human Epithelial Cells Discriminate between Commensal and Pathogenic Interactions with Candida albicans. PLoS ONE, 11 (4), e0153165. doi: 10.1371/journal.pone. 0153165

[18] Vautier, S., Drummond, R. A., Chen, K., Murray, G. I., Kadosh, D., Brown, A. J. P. et. al. (2014). Candida albicanscolonization and dissemination from the murine gastrointestinal tract: the influence of morphology and Th17 immunity. Cellular Microbiology, 17 (4), 445-450. doi: 10.1111/cmi.12388

[19] Kerimov, E. A. (2011). Issledovanie vzaimosvyazi kolichestvennoy vysevaemosti Candida spp. S faktor ami patogennosti griba u bol'nyh kandidozom zheludochno-kischechnogo trakta [Study of the interrelationship of quantitative inoculation Candida spp. with fingi pathogenicity factors in patients with candidiasis of the gastrointestinal tract]. Ukrainskiy zhurnal klinichnoi ta laboratornoi mediciny, 6 (1), $103-108$.

[20] Lisovskaya, S. A., Haldeeva, E. V., Gluschko, N. I., Parschakov, V. R. (2015). Analiz adgezivnoy aktivnosti klinicheskih schtammov Candida albicans, dydelennyh s kozhi bolnyh raznyh nozologicheskih grupp [Analysis of the adhesive activity of Candida albicans, isolated from skin of patients with different nosological groups]. Problemy medizinskoy mikologii, 17 (4), 66-68.

[21] Polishuk, O. I., V’yalyh, Zh. E., Yanovs'ka, V. V., Pokas, O. V., Makuschenko, O. S. (2008). Zastosuvannya micrometodu viznachennya adgezivnoi aktivnosti yak faktoru patogennosti microorganizmiv [Apply adhesive micromethod determining activity as a factor of pathogenicity of microorganisms]. Information paper № 30. Ukrmedpatentinform MOZ of Ukraine, 3. 